\title{
Parallel pathways of gene regulation: homologous regulators SWI5 and ACE2 differentially control transcription of $\mathrm{HO}$ and chitinase
}

\author{
Paul R. Dohrmann, ${ }^{1}$ Geraldine Butler ${ }^{2,4}$ Katherine Tamai, $^{2}$ Scott Dorland, ${ }^{1}$ Jonathan R. Greene, ${ }^{3}$ \\ Dennis J. Thiele, ${ }^{2}$ and David J. Stillman ${ }^{1,5}$ \\ ${ }^{1}$ Department of Cellular, Viral, and Molecular Biology, University of Utah Medical Center, Salt Lake City, Utah 84132 \\ $\mathrm{USA}^{2}{ }^{2}$ Department of Biological Chemistry, University of Michigan Medical School, Ann Arbor, Michigan 48109-0606 USA; \\ ${ }^{3}$ Schering-Plough Research, Bloomfield, New Jersey 07003 USA
}

\begin{abstract}
Two independent pathways of transcriptional regulation that show functional homology have been identified in yeast. It has been demonstrated previously that SWI5 encodes a zinc finger DNA-binding protein whose transcription and cellular localization both are cell cycle regulated. We show that $A C E 2$, whose zinc finger region is nearly identical to that of $S W I 5$, shows patterns of cell cycle-regulated transcription and nuclear localization similar to those seen previously for SWI5. Despite their similarities, SWI5 and ACE2 function in separate pathways of transcriptional regulation. SWI5 is a transcriptional activator of the $H O$ endonuclease gene, whereas $A C E 2$ is not. In contrast, $A C E 2$ is a transcriptional activator of the CTS1 gene (which encodes chitinase), whereas SWI5 is not. An additional parallel between the SWI5/HO pathway and the ACE2/CTS1 pathway is that $H O$ and CTS1 both are cell cycle regulated in the same way, and $H O$ and CTS1 both require the SWI4 and SWI6 transcriptional activators. Overproduction of either SWI5 or ACE2 permits transcriptional activation of the target gene from the other pathway, suggesting that the DNA-binding proteins are capable of binding in vivo to promoters that they do not usually activate. Chimeric SWI5/ACE2 protein fusion experiments suggest that promoter specificity resides in a domain distinct from the zinc finger domain.
\end{abstract}

[Key Words: Transcription; cell cycle; nuclear localization; zinc finger; CTS1]

Received September 16, 1991; revised version accepted November 5, 1991.

One of the major questions in molecular biology is how transcription is regulated. It is generally believed that transcription is controlled by site-specific DNA-binding proteins that interact with control regions of promoters. These transcriptional regulators are often classified by DNA-binding motif, such as zinc finger, helix-loop-helix, or homeo domain (Johnson and McKnight 1989; Gutman and Wasylyk 1991). For many genes the pattern of gene regulation is determined simply by the promoter sequences and the proteins that bind there. However, the situation becomes more complicated because several proteins containing the same DNA-binding motif can recognize the same DNA sequence in vitro. This is particularly striking for homeo-domain proteins, which show similar DNA-binding specificity in vitro even though they regulate different genes in vivo (Hayashi and Scott 1990). It is becoming increasingly clear that in vitro interactions between a DNA-binding protein and a

\footnotetext{
${ }^{4}$ Present address: Department of Biochemistry, University College Dublin, Dublin 4, Ireland.

${ }^{5}$ Corresponding author.
}

promoter do not always reflect the transcriptional regulation seen in vivo. Recently, two transcriptional activators from Saccharomyces cerevisiae with similar DNAbinding domains, ACE2 and SWI5, have been described (Butler and Thiele 1991).

The ACE2 gene is homologous to the SWI5 gene, which encodes a zinc finger protein that functions as an activator of $H O$ gene transcription (Stillman et al. 1988; Butler and Thiele 1991). The two genes show $37 \%$ similarity over their entire length. The zinc finger DNAbinding domains of these two proteins are very highly conserved, with $83 \%$ identity in amino acid sequence. The similarity of the two DNA-binding domains rises to $95 \%$ if one includes conservative substitutions. More importantly, the amino acid residues predicted to make nucleotide-specific contacts with DNA, based on the zinc finger-DNA cocrystal (Pavletich and Pabo 1991), are the same for these two proteins (Fig. 1). We would therefore predict that SWI5 and ACE2 bind to the same DNA sequences.

The $A C E 2$ gene was isolated as a multicopy suppressor of an ace 1 defect, based on its ability to permit growth in 


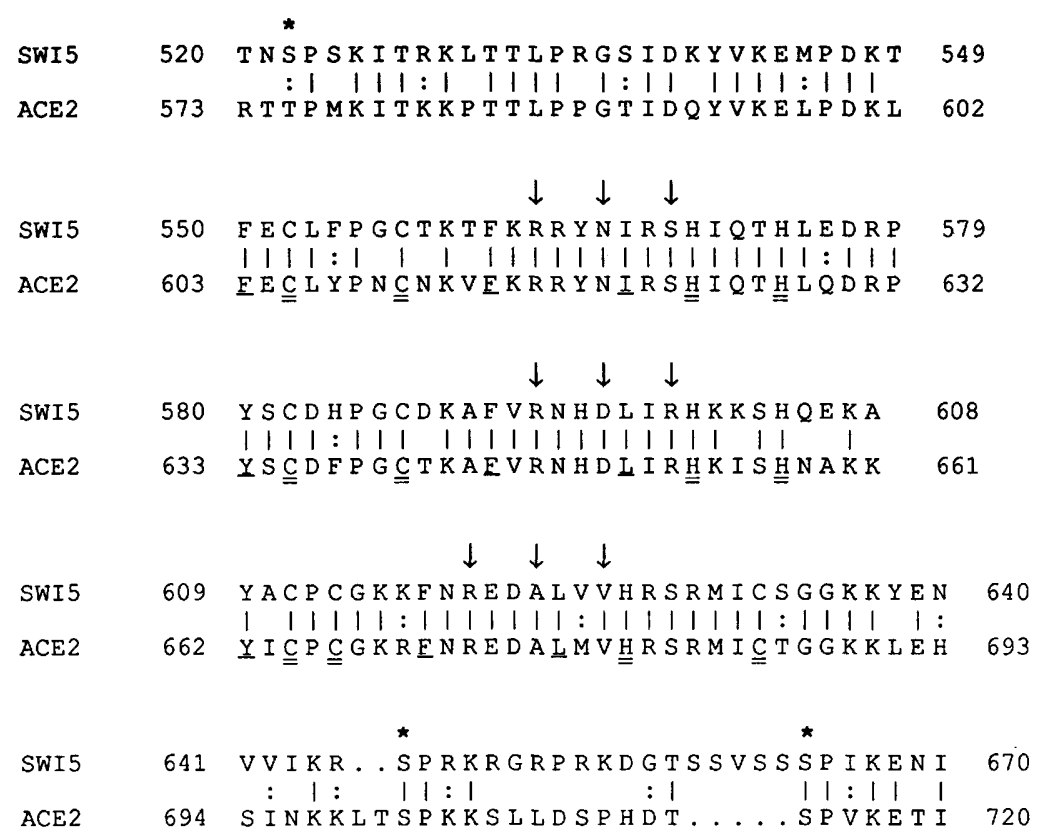

Figure 1. The DNA-binding domains of Swi5 and Ace 2 are highly conserved. The three zinc fingers of Swi5 and Ace 2 and surrounding regions are aligned. Residues identical in Swi5 and Ace2 are shown with a vertical line; conservative substitutions are shown with a colon. The residues conserved in zinc fingers are indicated as follows: Conserved hydrophobic residues are underlined; conserved cysteines and histidines are doubly underlined. Vertical arrows indicate residues that are predicted to contact DNA based on the zinc finger-DNA cocrystal (Pavletich and Pabo 1991). The asterisks (*) indicate serine residues in SWI5 whose phosphorylation determines subcellular localization (Moll et al. 1991).
694 S INKKLTSPKKSLLDSPHDT . . . SPVKETI 720 the presence of high environmental concentrations of copper (Butler and Thiele 1991). ACE1 is required for activation of the CUP1 locus, which encodes metallothionein, and an ace 1 mutant strain is therefore copper sensitive (Thiele 1988).

SWI5 was identified as a transcriptional activator of the yeast $H O$ gene (Stern et al. 1984). $H O$ encodes an endonuclease that initiates mating-type interconversion, and in a swi5 mutant $\mathrm{HO}$ is not expressed and matingtype switching does not occur (Nasmyth and Shore 1987; Herskowitz 1988|. HO is expressed in one of the two cells resulting from mitotic division, the mother cell, but it is not expressed in daughter cells (Strathern and Herskowitz 1979). SWI5 encodes a protein that binds in vitro to a site in the $H O$ promoter and plays a role in determining the differential expression of $\mathrm{HO}$ in mothers and daughters (Nasmyth 1987; Nasmyth et al. 1987; Stillman et al. 1988).

Nasmyth et al. $(1987,1990)$ have shown that SWI5 is cell cycle regulated in two distinct ways. First, it is transcriptionally regulated such that maximal mRNA levels accumulate in the $G_{2}$ phase of the cell cycle (Nasmyth et al. 1987). Second, the entry of Swi5 protein into the nucleus is regulated in the cell cycle (Nasmyth et al. 1990): Swi5 protein is cytoplasmic when synthesized in $\mathrm{G}_{2}$; at mitosis, it moves to the nucleus and then rapidly disappears.

In this report we show that $A C E 2$ is a transcriptional activator of the CTS1 gene. The CTS1 gene encodes chitinase, which is needed for separation of mother and daughter cells during mitotic growth (Kuranda and Robbins 1991). We also show that ACE2 displays a pattern of cell cycle-regulated transcription and cellular localization identical to that seen for SWI5, and that CTS1 and $H O$ display a similar pattern of cell cycle-regulated transcription. The structural similarity of the two transcrip- tional activators prompted us to determine whether they share functions in vivo. Despite their similarities in cell cycle regulation and DNA-binding domains, SWI5 and $A C E 2$ regulate the transcription of different genes.

\section{Results}

\section{Transcriptional regulation of ACE2}

$A C E 2$ and $S W I 5$ encode homologous zinc finger proteins. Because SWI5 expression is cell cycle regulated, we determined whether $A C E 2$ is differentially expressed during the cell cycle. Yeast cells were arrested with the mating pheromone $\alpha$-factor, inoculated into fresh media lacking $\alpha$-factor, and allowed to grow synchronously through several cell cycles. Samples were taken at 10min intervals, RNA was extracted, and ACE2 mRNA levels were assayed by blot hybridization (Fig. 2). ACE2 RNA is absent from $\alpha$-factor-arrested cells and from cells in $\mathrm{G}_{1}$, with maximal RNA accumulation late in the cell cycle, identical to that seen for SWI5. It is worth noting that both $A C E 2$ and SWI5 are very low-abundance transcripts.

Because ACE2 and SWI5 show identical patterns of mRNA accumulation, we compared the DNA sequences within their promoter regions. An exact 12 of 12 nucleotide match was seen (Fig. 3). Recently, two genes encoding $\mathrm{G}_{2}$ or mitotic cyclins were cloned from $S$. cerevisiae, and the pattern of cell cycle regulation of these genes is identical to that seen for SWIS (Ghiara et al. 1991; Surana et al. 1991). We therefore compared the putative promoter regions of these mitotic cyclin genes, $C L B 1 / S C B 1$ and $C L B 2$, with the $A C E 2 / S W I 5$ match, and significant homology was seen. It should be noted that the two 9/12 matches identified for the SCB2 gene are actually in tandem. This high degree of similarity seen in 


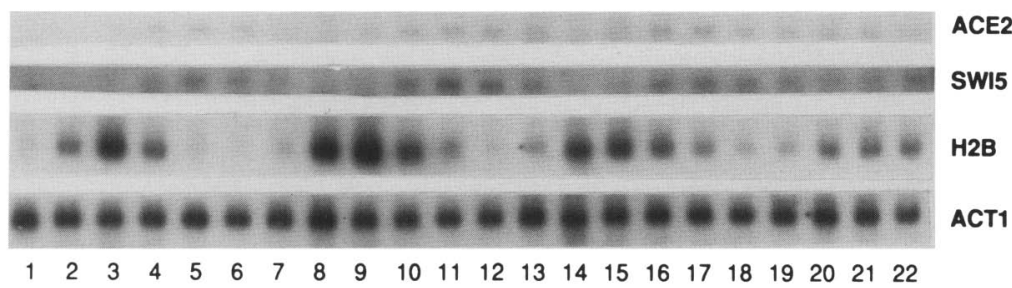

Figure 2. $A C E 2$ mRNA levels are cell cycle regulated. Wild-type cells were synchronized by an $\alpha$-factor block-and-release protocol. RNA samples were prepared from $\alpha$-factor-blocked cells (lane 1) and at 10-min intervals following release into fresh medium (lanes 2-22). RNA blot hybridization was performed to assay mRNA levels for $A C E 2, A C T 1$, histone $H 2 B$, and $S W I 5 . A C T 1$ serves as an internal control, $H 2 B$ RNA levels rise in late $G_{1}$ and $S$ phases (Hereford et al. 1981), and SWI5 RNA levels rise in $\mathrm{G}_{2}$ phase (Nasmythet al. 1987). promoters of $\mathrm{G}_{2}$-expressed genes suggests that this sequence plays a functional role in transcriptional regulation. Functional studies will be required to determine the relevance of these promoter sequences in gene regulation.

\section{Subcellular localization of Ace2}

Because Ace2 shows sequence similarity to Swi5, and because the subcellular localization of Swi5 varies within the cell cycle (Nasmyth et al. 1990), we decided to examine the localization of Ace2. The localization of Ace 2 in the cell was determined using a fusion between the entire Ace 2 open reading frame (ORF) and the Escherichia coli $\beta$-galactosidase gene (lacZ) on a multicopy plasmid. As in the case of Ace2, this large Ace2-LacZ fusion is biologically active as a multicopy suppressor of the copper-sensitive phenotype of an ace1 deletion (data not shown; Butler and Thiele 1991). The fusion protein was detected by indirect immunofluoresence. In an asynchronous culture expressing the Ace2- $\beta$-galactosidase fusion, several patterns of fluorescent staining can be seen (Fig. 4a). Some cells do not stain with antibody; this may be because Ace 2 is not always expressed or may be the result of differences in antibody permeability in individual cells. In some cells, staining is predominantly cytoplasmic. Nuclear staining is seen only in cells with clearly visible mother and daughter nuclei or in cells that are small and unbudded; these cells are in $G_{1}$ phase. The morphology of a yeast cell is a reliable indicator of position within the cell cycle (Pringle and Hartwell 1981). A similar pattern of localization was seen using anti-c-myc antibody, and a construct in which a 10amino-acid epitope derived from the c-Myc protein was inserted before the stop codon of Ace2 (G. Butler and D.J. Thiele, unpubl.). The differential localization is therefore unlikely to be simply the result of expression of the large Ace2-LacZ fusion protein. Such differential localization is very similar to the cell cycle-regulated localization of Swi5, which is found in the nucleus of cells in late $M$ and $G_{1}$ phases but is cytoplasmic at all other stages of the cell cycle (Nasmyth et al. 1990).

The localization of Ace 2 during the cell cycle was analyzed further by arresting cells carrying the Ace2- $\beta$ galactosidase fusion plasmid at specific stages of the cell cycle. Cells were arrested in early $M$ phase by treatment with nocodazole, a microtubule-depolymerizing drug (Jacobs et al. 1988). Cells arrested with nocodazole display

distinct cytoplasmic staining, in a punctate fashion (Fig. 4b). Punctate cytoplasmic staining was also seen when Swi5 was overproduced (Nasmyth et al. 1990) and may be a result of overproduction from a multicopy plasmid. $M A T$ a cells were arrested in $\mathrm{G}_{1}$ using $\alpha$-factor, and Ace 2 is predominantly nuclear localized (Fig. 4c). It should be noted that during long treatments with $\alpha$-factor $(>3 \mathrm{hr}$ ) the $\beta$-galactosidase antigen is again found in the cytoplasm, which may result from proteolysis of the Ace2$\beta$-galactosidase fusion, particularly as Ace2 is not expressed during $\alpha$-factor arrest (see Fig. 2). In any case, these results suggest that the cellular distribution of Ace 2 very closely resembles that of Swi5. Both Swi5 and Ace 2 are localized to the cytoplasm of cells undergoing DNA synthesis (small buds, $S$ phase) or in early $M$ phase but are localized to the nucleus of cells completing cell division (in late $M$ or early $G_{1}$ ).

The regions of Swi5 required for nuclear localization recently have been identified (Moll et al. 1991). Cell cycle-dependent phosphorylation of three serine residues (amino acids 522, 646, and 664) by the yeast Cdc28 kinase is associated with regulated translocation to the nucleus. A comparison of the protein sequence of Swi5 and Ace2 (Fig. 1) shows that two of these serines (Ser-646 and Ser-664) are absolutely conserved in Ace2, and Ser522 in Swi5 has been replaced by a threonine in Ace2, which can be phosphorylated in a similar fashion. Sequences surrounding these residues have also been conserved and represent potential phosphorylation sites for Cdc28 kinase (Moreno and Nurse 1990). Therefore, it is very likely that localization of Ace2 and Swi5 is regulated in a similar fashion. Although the role of these residues in translocation of Ace 2 has not been determined, this is presently under investigation.

Differential nuclear localization is emerging as a very important mode of cellular regulation. Certain transcrip-

$\begin{array}{ll}\text { SWI5 } & 607 \text { before ATG } \\ \text { ACE2 } & 191 \text { before ATG } \\ \text { CLB1/SCB1 } & 349 \text { before ATG } \\ \text { CLB2 } & 297 \text { before ATG } \\ \text { CLB2 } & 285 \text { before ATG }\end{array}$

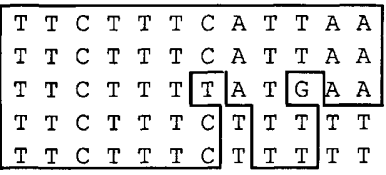

Figure 3. Promoter sequences in $\mathrm{G}_{2}$-expressed genes. The promoter sequences of $S W I 5$ and $A C E 2$ were compared, and a 12 nucleotide match was observed. This 12-nucleotide consensus was then used to search the promoters of the $\mathrm{G}_{2}$ cyclin genes $C L B 1 / S C B 1$ and $C L B 2$. The two $S C B 2$ matches are in tandem. 

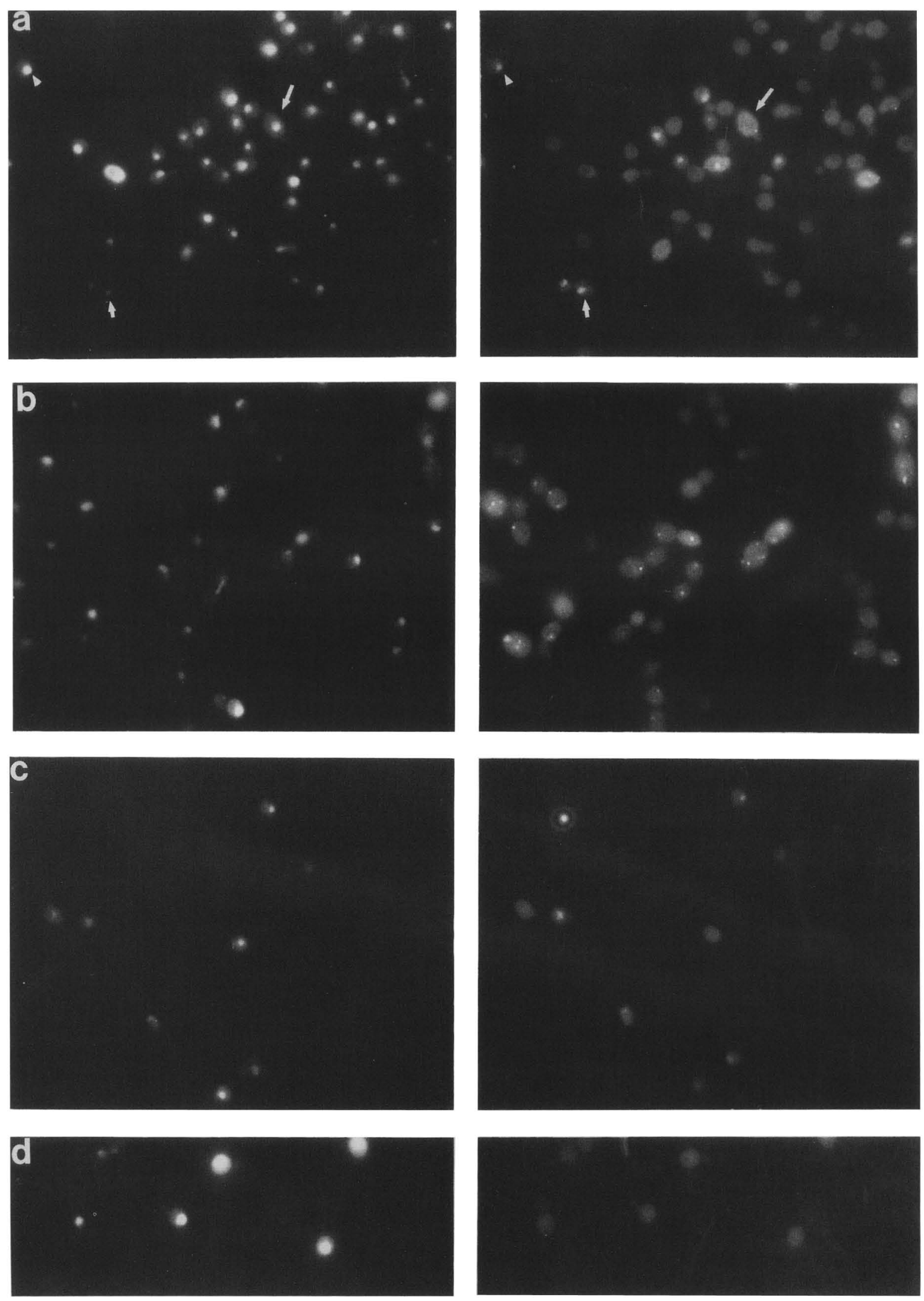

Figure 4. (See facing page for legend.) 
tion factors, such as the glucocorticoid receptor or c-fos, remain cytoplasmic until a specific stimulus is applied (hormone or serum factors), and then enter the nucleus (Picard and Yamamoto 1987; Roux et al. 1990). The yeast Cdc46 protein, which is required for DNA replication, enters the nucleus in a cell cycle-dependent fashion very similar to both Swi5 and Ace2 (Hennessy et al. 1990). The Drosophila fsl(Ya) protein, required for mitosis, moves between the cytoplasm and the nuclear envelope (and an inactive and active state) in a cell cycle-dependent manner (Lin and Wolfner 1991). Therefore, it appears that Ace 2 is a new member of a class of proteins that show regulated subcellular localization.

\section{ACE2 is a regulator of CTS1}

Chitinase is needed to degrade the chitin septum joining mother and daughters. Kuranda and Robbins (1991) have cloned the CTS1 gene, which encodes chitinase, and have shown that disruption of the gene causes a defect in cell separation, which we refer to as clumpiness. We have observed that an ace 2 mutation also causes a clumpy phenotype (see below), and we decided to ask whether the CTS1 gene is transcriptionally regulated by $A C E 2$ or SWI5. RNA was prepared from four isogenic strains, and RNA blot hybridization analysis was performed with probes for CTS1 and ACT1 (actin). CTS1 mRNA is absent from the ace2 SWI5 and ace2 swi5 strains (Fig. 5). The ACE2 swi5 strain, however, has CTS1 mRNA levels equivalent to wild type. The results clearly demonstrate that $A C E 2$ is required for CTS1 expression, whereas SWI5 is not. The fact that the ace? mutation causes a drastic decrease in CTS1 mRNA levels suggests that $A C E 2$ is a major transcriptional activator of CTS1.

\section{CTS1 is cell cycle regulated}

The pattern of expression of the CTS1 gene within the cell cycle was determined. One rationale for this experiment is that cell separation, promoted by chitinase, is a landmark of the yeast cell cycle. An additional rationale is that $A C E 2$ and $S W I 5$ are cell cycle regulated in an identical fashion $\left(\mathrm{G}_{2}\right.$ expression) and that $H O$, the only gene known to be regulated by $S W I 5$, is also cell cycle regulated $\left(\mathrm{G}_{1}\right.$ expression). A Northern blot containing RNA samples from cells synchronized by an $\alpha$-factor arrest-and-release protocol was hybridized with a CTS1 probe (Fig. 6). CTS1 is expressed during the $\alpha$-factor

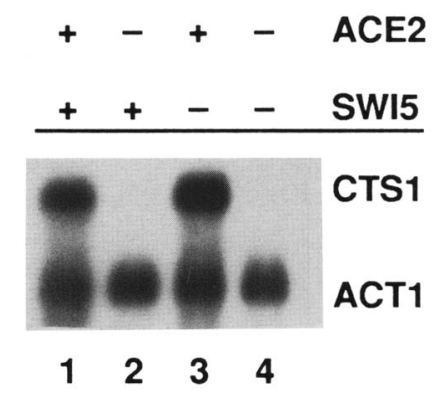

Figure 5. ACE2 is an activator of the CTS1 gene. A Northern blot was hybridized with a CTS1 probe and an $A C T 1$ probe as an internal control. RNA was prepared from the following isogenic strains: (Lane 1) DY1119 wild type; (lane 2) DY1151 ace2 SWI5; (lane 3) DY1000 ACE2 swi5; (lane 4) DY1149 ace2 swi5.

block, but the CTS1 RNA disappears within 10 min after growth in fresh media and remains off during the first cell cycle. CTS1 RNA appears during the $\mathrm{G}_{1}$ phase of the second cell cycle, disappears during $S$ and $G_{2}$, and reappears during $G_{1}$ of the third cell cycle.

CTS1 RNA accumulation clearly is periodic during the cell cycle, with maximal RNA levels seen in $G_{1}$ phase. As controls, we compared the pattern of CTS1 expression (Fig. 6) with the expression of other genes known to be expressed early in the cell cycle, histone $\mathrm{H} 2 \mathrm{~B}$ and $\mathrm{HO}$ (Hereford et al. 1981; Nasmyth 1983). The periodicity of CTS1 expression is similar to that of $H O$, in $\mathrm{G}_{1}$. Maximal expression from these two genes occurs slightly before that of $H 2 B$, which is expressed in late $G_{1}$ and $S$ phases of the cell cycle. It has been demonstrated previously that $H O$ mRNA is absent during $\alpha$-factor arrest (Nasmyth 1983). CTS1 mRNA is present during exposure to mating pheromone, and in this respect CTS1 regulation differs from $H O$. It appears that the CTS1 gene is transcribed during $\alpha$-factor arrest, although it is possible that $\alpha$-factor stabilizes previously synthesized CTS1 mRNA. HO and CTS1 regulation are similar in that mRNA accumulation is substantially reduced during the first cell cycle following release from $\alpha$-factor arrest (Nasmyth et al. 1987; Breeden and Mikesell 1991). HO and CTS1 differ with repect to cell-type regulation. The HO gene is inactive in diploids (Jensen et al. 1983), whereas the CTS1 gene is expressed in diploids (data not shown).

The SWI4 and SWI6 genes were identified as transcriptional activators of $\mathrm{HO}$ and are involved in the cell cycle

Figure 4. Differential nuclear localization of an $A C E 2-\beta$-galactosidase fusion protein detected by indirect immunofluoresence. (a) Asynchronous culture (strain DTY59) transformed with the ACE2- $\beta$-galactosidase fusion plasmid YEpACE2-lacZ. (Left) DAPIstained DNA; (right) the localization of $A C E 2-\beta$-galactosidase detected by staining with anti- $\beta$-galactosidase primary and FITCconjugated secondary antibodies. The arrowhead indicates nuclear localization in a $\mathrm{G}_{1}$ cell, the short arrow indicates nuclear localization in a cell just after mitosis, and the longer arrow indicates cytoplasmic fluoresence in a $\mathrm{G}_{2}$ cell prior to nuclear division. $(b)$ Cells (strain DTY59/YEpACE2-lacZ) synchronized in mitosis by growth in media containing nocodazole, and stained as in $a$. (c) Cells (strain CG378/YEpACE2-lacZ) synchronized in $\mathrm{G}_{1}$ by treatment with the mating pheromone $\alpha$-factor. This strain shows the same staining pattern as $a$ when grown in the absence of $\alpha$-factor (data not shown). (d) Cells (DTY59) transformed with the parent vector YEp367, to show degree of nonspecific fluoresence. 
Figure 6. CTS1 mRNA levels are cell cycle regulated. Wild-type cells were synchronized by an $\alpha$-factor block-and-release protocol. RNA samples were prepared from $\alpha$-factor-blocked cells (lane 1) and at 10-min intervals following release into fresh medium (lanes 2-22). RNA blot hybridization was performed to assay mRNA levels for CTS1, ACT1, histone $H 2 B$, and $H O$. ACT1 serves as an internal control, $H 2 B$ RNA levels rise in late $G_{1}$ and $S$ phases (Hereford et al. 1981), and HO RNA levels rise in $\mathrm{G}_{1}$ phase (Nasmyth 1983). The same aliquots of cells were used in this experiment and in the experiment shown in Fig. 2.

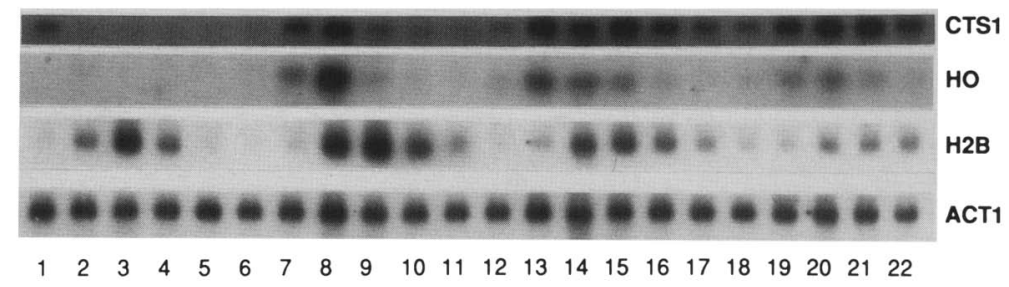

regulation of $H O$ (Stern et al. 1984; Breeden and Nasmyth 1987; Breeden and Mikesell 1991). SWI4 and SWI6 are components of a cell cycle-regulated DNAbinding activity and are also transcriptional activators of the $\mathrm{G}_{1}$ cyclins of yeast, CLN1,CLN2, and HSC26 (Andrews and Herskowitz 1989; Nasmyth and Dirick 1991; Ogas et al. 1991). Because CTS1 is expressed in $\mathrm{G}_{1}$, as are $H O$ and the $G_{1}$ cyclins, it seemed possible that CTS1 might be regulated by $S W I 4$ and SWI6. RNA was prepared from swi4 and swi6 mutant strains and from an isogenic wild-type strain, and Northern blot analysis demonstrates that the CTS1 transcript is drastically reduced in swi4 and swi6 mutant strains (Fig. 7).

\section{Characterization of ace 2 swi5 double mutants}

$A C E 2$ and SWI5 encode homologous cell cycle-regulated transcription factors. One might predict that genes encoding cell cycle-regulated transcription factors would be essential, but a strain with a null mutation in either $A C E 2$ or SWI5 is viable. Because ACE2 and SWI5 are homologous, they could provide redundant functions. To answer this question a diploid strain with disrupted alleles of $A C E 2$ and SWI5 was created, this doubly heterozygous diploid strain was then sporulated, and tetrads were dissected. We found that haploid ace2 swi5 double mutant strains are viable. This result does not exclude the possibility that another, unidentified gene provides an essential function and thus permits viability of an ace 2 swi5 double mutant.

The ace2 swi5 and the ace2 SWI5 haploid segregants dissected from the ACE2/ace2 SWI5/swi5 diploid strain had an altered colony morphology. The ace 2 mutants had surface invaginations and appeared rough at the colony periphery, in contrast to the normal smooth, lustrous colony surface. Microscopic examination revealed a clumpy phenotype (Fig. 8). The ace2 swi5 double mutant is extremely clumpy, the ace 2 single mutant is significantly clumpy, and the swi5 single mutant shows only modest clumpiness. Comparing the extent of the clumpy phenotype of the isogenic strains (Table 1) suggests that the clumpy phenotype is additive in the double mutant. When the clumpy cells were stained with Calcofluor, fluorescence was seen at the junctions between cells (data not shown). This confirms that the sites of attachment between cells are the chitin septa.
The ace2 swi5 double mutant is significantly more clumpy than the ace2 SWI5 strain (Table 1). However, no difference in CTS1 RNA levels can be detected between an ace 2 swi5 double mutant and an ace2 SWI5 mutant, even when the gel shown in Figure 5 is heavily overexposed (data not shown). This implies that the absence of CTS1 RNA is not the sole cause of the clumpy phenotype. We would therefore suggest that the swi5 mutation contributes to a clumpy phenotype by some means other than control of CTS1 mRNA levels. We speculate that SWI5 is a transcriptional regulator of other, unidentified genes important in cell separation.

A chromosomal $\mathrm{HO}:$ lacZ reporter (Breeden and Nasmyth 1987) was used to quantitate $H O$ promoter activity in four isogenic strains differing only at the ACE2 and SWI5 loci. As shown in Table 1, a swi5 mutation reduces $H O$ expression 70 -fold. The ace 2 single mutation has minimal quantitative effects on $H O$ : lacZ activity, whether the strain is SWI5 or swi5. Therefore, we

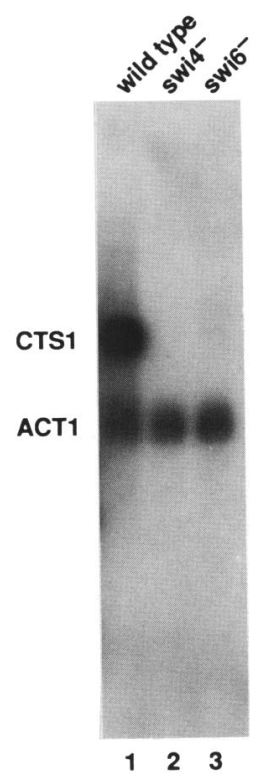

Figure 7. SWI4 and SWI6 are activators of the CTS1 gene. A Northern blot was hybridized with a CTS1 probe and an ACT1 probe as an internal control. RNA was prepared from the following isogenic strains: (Lane 1) DY131 wild type; (lane 2) DY1115 swi4; (lane 3) DY1114 swi6. 
A. ACE2 SW15

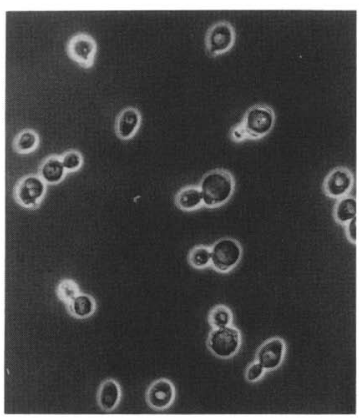

C. ace2 SWI5

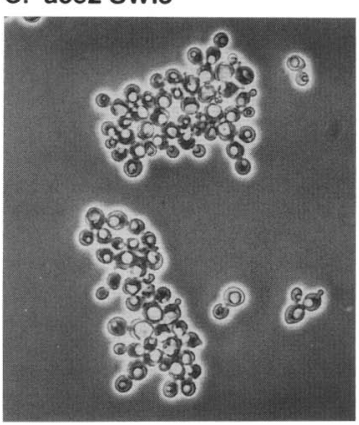

B. ACE2 swi5

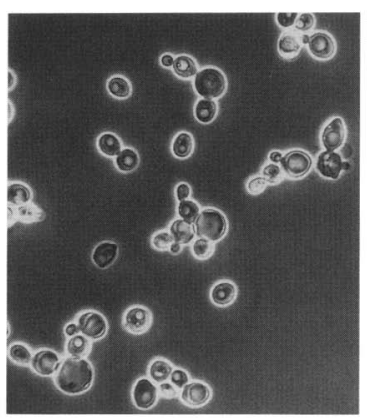

D. ace2 swi5

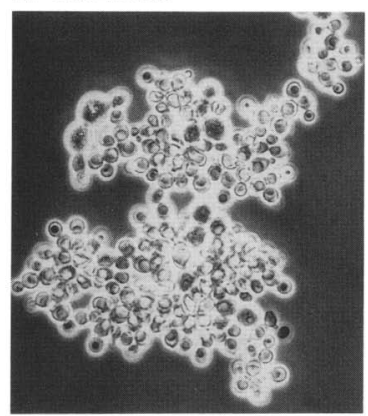

Figure 8. Mutations in ace2 or swi5 lead to a clumpy phenotype. Logarithmically growing cells were sonicated before phase-contrast micrographs were taken with a Nikon Optiplot microscope. The four strains are isogenic, except for the following mutations: $(A)$ DY1119 wild type; $(B)$ DY1000 ACE2 swi5; (C) DY1151 ace2 SWI5; (D) DY1149 ace2 swi5.

conclude that $A C E 2$ is not a transcriptional regulator of $H O$, at least under the conditions assayed.

\section{Suppression by overproduction of ACE2 or SWI5}

$A C E 2$ and SWI5 regulate distinct genes, despite the similarity of Ace 2 and Swi5 in their DNA-binding domains, cell cycle-regulated transcription, and regulated cellular localization. Although normal expression from the chromosomal ACE2 gene does not activate $H O$ expression in a swi5 mutant (Table 1), we reasoned that increased levels of Ace 2 might activate $H O$ expression in the absence of SWI5. A multicopy plasmid containing ACE2 (YEp$A C E 2)$ was transformed into an ace2 swi5 mutant strain. The strain contains the lacZ gene driven by the HO pro-

Table 1. SW15 and ACE2 genotype differentially affect HO expression, clumpiness, and CTS1 expression

\begin{tabular}{|c|c|c|c|c|}
\hline & Strain & $\begin{array}{l}\text { HO : lacZ } \\
\text { expression } \\
(\%)\end{array}$ & Clumpiness & $\begin{array}{l}\text { CTS1 } \\
\text { expression }\end{array}$ \\
\hline DY131 & SWI5 ACE2 & 100.0 & - & +++ \\
\hline DY999 & swi5 ACE2 & 1.4 & ++ & +++ \\
\hline DY1148 & SWI5 ace2 & 92.4 & $+t+t$ & - \\
\hline DY1150 & swi5 ace2 & 1.7 & $+++++t$ & - \\
\hline
\end{tabular}

Clumpiness is based on microscopic inspection. $\mathrm{HO}: 1 \mathrm{acZ}$ expression is given as a percentage of the wild-type strain. CTS1 expression is from Fig. 5. moter, integrated at the $H O$ chromosomal locus. Measurements of $l a c Z$ expression (Fig. 9A) demonstrate that $A C E 2$ overexpression can partially complement the swi5 defect. The YEpACE2 plasmid in the ace2 swi5 strain also makes the cells less clumpy than in an ACE2 swi5 strain.

The reciprocal experiment was performed with a multicopy plasmid expressing SWI5 transformed into an ace2 swi5 mutant strain (Fig. 9A). The increase in SWI5 expression provided by the YEp plasmid was not sufficient to complement the ace2 defect in CTS1 gene activation. However, the multicopy plasmid containing SWI5 (YEpSWI5) did partially suppress the clumpiness of the ace 2 swi5 double mutant. Therefore, either very low levels of CTS1 are sufficient for reversion of the clumpy phenotype or the increased expression of an as yet unidentified target gene of SWI5 suppresses the clumpy phenotype. To obtain higher levels of Swi5, the ace2 swi5 mutant was transformed with a plasmid that has SWI5 function under the control of the inducible GAL1 promoter (Stillman et al. 1988). When these cells were grown on glucose medium Swi5 was not expressed and no CTS1 transcript was seen. Cells were grown on galactose medium to induce high-level expression of Swi5. Under these conditions CTS1 transcript levels approach the levels observed in wild-type strains (Fig. 9B).

$A C E 2$ and SWI5 act as transcriptional activators for the CTS1 and HO target genes, respectively. Each of

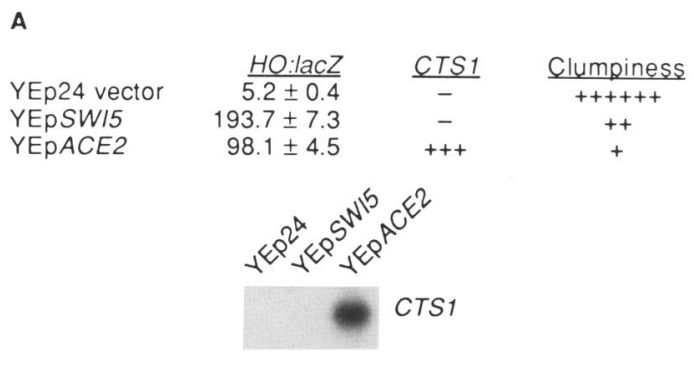

B

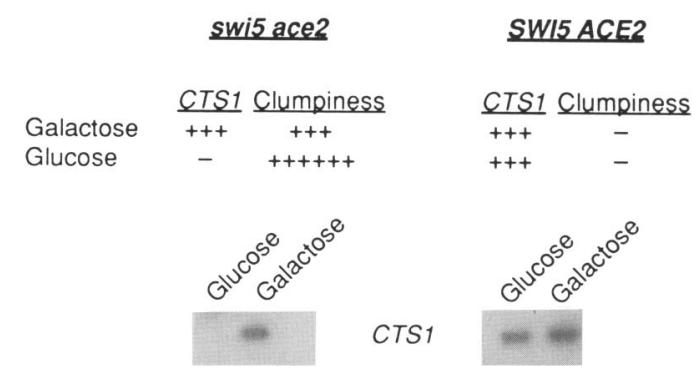

Figure 9. Complementation of ace2 or swi5 defect by overproduction. (A) Multicopy plasmids YEp24 or YEp24 with SWI5 or $A C E 2$ were transformed into strain DY1149 (ace2 swi5) and grown under uracil selection. $(B) p G A L: S W I 5$ plasmid was transformed into strain DY1149 (ace2 swi5), which was grown either on SC-Ura (containing $2 \%$ glucose) or SC-Ura $+\mathrm{Gal}$ (containing $2 \%$ galactose) media. $\mathrm{HO}: 1 \mathrm{lacZ}$ activity is given in quantitative units from ONPG assays (Breeden and Nasymth 1987), CTS1 activity is from the Northern blot shown, and clumpiness was determined from microscopic observation. 
these zinc finger proteins, when expressed from single copy (either YCp or chromosomal), does not activate transcription of the incorrect target gene. However, overproduction of a DNA-binding protein leads to transcriptional activation of the incorrect target gene. We would suggest that an increase in the Ace 2 protein levels in vivo will allow it to interact productively with the $H O$ promoter and act as a transcriptional activator. Similarly, although SWI5 does not normally interact with the CTS1 promoter, these results suggest that it can when expressed at elevated levels. We cannot rule out the possibility that these effects may be indirect.

\section{Chimeric transcriptional activators}

To address the question of what part of the Ace2 and Swi5 zinc finger proteins are responsible for promoter specificity, protein fusions that exchange domains between Ace2 and Swi5 were constructed. As shown diagrammatically in Figure 10A, Ace2 and Swi5 contain restriction sites $K p n I$ and $C l a I$, respectively, at an equivalent location upstream of the zinc fingers. The restriction sites allowed us to conveniently separate the amino-terminal domain of each protein from the zinc finger domain and to construct protein chimeras by exchanging zinc finger domains. An ace2 swi5 mutant strain was transformed with either a CEN plasmid vector (as a control) or the same plasmid containing either SWI5(ClaI-KpnI), ACE2, SWI5 : ACE2(Zn), or ACE2 : $S W I 5(\mathrm{Zn})$. The transformants were scored for $H O: 1 a c Z$ expression, CTS1 mRNA levels, and clumpy phenotype (Fig. 10B).

The two chimeras gave very different results when CTS1 mRNA levels and clumpiness were analyzed. The SWI5 : ACE2(Zn) fusion did not appreciably alter CTS1 expression or clumpiness in the ace 2 swi5 mutant strain. In contrast, the $A C E 2: S W I 5(\mathrm{Zn})$ chimera significantly stimulated CTS1 expression and reduced the clumpiness to that seen in an ACE2 swi5 strain. We interpret this result to mean that the amino-terminal domain of Ace 2 is required for CTS1 promoter activation. This suggests that either zinc finger can function to promote activation of the CTS1 promoter but that promoter specificity resides in the amino-terminal domain.

The results with the $H O: l a c Z$ reporter are less clear. Only a slight increase in activity of the $H O$ gene reporter was seen with either chimera. The region of Swi5 needed for $H O$ promoter specificity could be encoded by DNA sequences that span the ClaI site used to make the chimeras; therefore, neither chimera is completely functional at HO. Alternatively, it is possible that the $S W I 5$ : $A C E 2(\mathrm{Zn})$ fusion protein is nonfunctional or unstable. The fact that the $A C E 2: S W I 5(\mathrm{Zn})$ chimera stimulates CTS1 transcription allows us to conclude that this construct produces a protein that is functional but is incapable of activating $\mathrm{HO}$ gene transcription.

\section{Discussion}

The activation of $H O$ by SWI5 presents an interesting

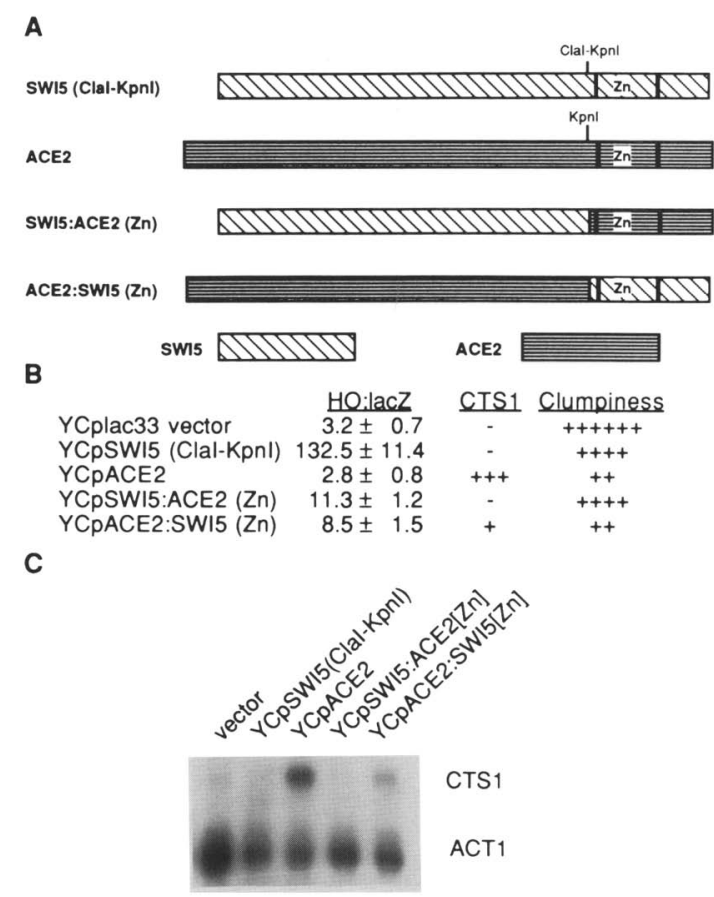

Figure 10. CTS1 activation by $A C E 2: S W I 5(\mathrm{Zn})$ chimera. $(A)$ Diagram of YCpSWI5(ClaI-KpnI), YCpACE2, YCpSWI5 : ACE2 $(\mathrm{Zn})$, and YCpACE2 : $S W I 5(\mathrm{Zn})$ genes. The genes are aligned at the zinc finger domains. The ClaI site of Swi5 was converted to a KpnI site, generating SWI5(ClaI-KpnI). The KpnI sites of $S W I 5(C l a I-K p n I)$ and $A C E 2$ were used to exchange domains and create the chimeras. Swi5 is 709 amino acids in length, with the zinc finger encompassing amino acids 550-637. The ClaI site encodes amino acids 538-539. Ace 2 is 770 amino acids in length, with the zinc finger encompassing amino acids 603-690. The KpnI site encodes amino acids 589-590. The ClaI site of $S W I 5$ and the KpnI site of $A C E 2$ are at equivalent positions 11 and 13 amino acids, respectively, upstream of the zinc finger. $(B)$ Strain DY1 149 (ace2 swi5) was transformed with the indicated single-copy plasmid and grown under uracil selection. $H O$ : $l a c Z$ activity is given in quantitative units from ONPG assays (Breeden and Nasymth 1987), CTS1 activity is from the Northern blot shown in $C$, and clumpiness was determined from microscopic observation. $(C)$ Northern blot hybridized with CTS1 and $A C T 1$ probes.

pattern of transcriptional regulation. The SWI5 gene is transcribed in the $\mathrm{G}_{2}$ phase of the cell cycle (Nasmyth et al. 1987). The newly synthesized protein remains cytoplasmic until mitosis, when it moves into the nucleus (Nasmyth et al. 1990). Swi5 is present in the nucleus in $\mathrm{G}_{1}$, where apparently it rapidly disappears. $H O$, the only known gene activated by SWI5, is not expressed until later in the cell cycle, in late $\mathrm{G}_{1}$ after START (Nasmyth 1983). The inactivity of the $H O$ promoter in early $G_{1}$ is not the result of a lack of competence on the part of Swi5. Nasmyth et al. (1990) have used an HO promoter deletion that is no longer START dependent and have shown that this promoter is activated when Swi5 moves into the nucleus. One of the most interesting facets of this pattern of transcriptional regulation is the asymmet- 
ric expression of $H O$. $H O$ is only expressed in one of the two cells produced from mitotic division, the mother cell. The mechanism of this mother cell-specific expression is not understood, but several experiments have implicated SWI5 in mother/daughter control (Nasmyth 1987; Nasmyth et al. 1987).

We have identified a similar pattern of transcriptional regulation of CTS1 by ACE2. ACE2 is transcribed in $\mathrm{G}_{2}$, and the protein product remains cytoplasmic until late in mitosis. CTS1, the gene activated by $A C E 2$, is expressed in late $G_{1}$ phase of the cell cycle. These two regulatory pathways, SWI5 activation of $H O$ and ACE2 activation of CTS1, show a number of common features: The transcription factor gene is expressed in $G_{2}$, the transcription factor shows cell cycle-dependent cellular localization, and the target gene is expressed late in $G_{1}$. The SWI4 and SWI6 genes are required for expression of both $H O$ and CTS1, as well as the $\mathrm{G}_{1}$ cyclins of yeast (Breeden and Mikesell 1991; Nasmyth and Dirick 1991; Ogas et al. 1991). Although these two regulatory pathways reflect the same pattern, they are clearly distinct pathways. There is no cross talk between the SWI5/HO pathway and the ACE2/CTS1 pathway. This is shown most clearly by the fact that SWI5 cannot function as an activator of CTS1 and that ACE2 cannot activate $H O$. (This is not true when the transcription factors are overexpressed; see below.)

The CTS1 gene encodes chitinase, which is needed for cell separation (Kuranda and Robbins 1991). The final event in the yeast cell cycle is the formation of the septum, composed of the polysaccharide chitin, which joins the mother cell to the daughter (Byers 1981; Cabib and Roberts 1982). The chitinase enzyme is needed to degrade the chitin junction between cells and thus allows the daughter cell to begin an independent existence. Because cell separation is a landmark of the yeast cell cycle it is not surprising that CTS1 expression is cell cycle regulated. Part of the chitinous septum remains with the mother after cell separation, resulting in the structure known as the bud scar. In contrast, the daughter cell is born without a bud scar.

Cell division in budding yeast is inherently asymmetric, and it is possible that the CTS1 gene, like HO, will be asymmetrically expressed in mothers and daughters. Because there are many analogies between the SWI5/HO and $A C E 2 / C T S 1$ regulatory pathways, it is reasonable to consider the idea that CTS1 might be expressed in only one of the two progeny from cell division. The asymmetry of the bud scar is consistent with this notion. Experiments are in progress to address this question.

In addition to common patterns of cell cycle-regulated expression and localization, the Ace 2 and Swi5 proteins share structural features. Both proteins are roughly the same size - 770 amino acids for Ace2 and 709 amino acids for Swi5. Both proteins contain three zinc fingers, with the first two being TFIIIA-like C- $X_{4}-\mathrm{C}-X_{12}-\mathrm{H}-X_{3}-\mathrm{H}$ zinc fingers, and the third zinc finger a very unusual $\mathrm{C}-X_{1}-\mathrm{C}-X_{12}-\mathrm{H}-X_{5}-\mathrm{C}$ structure. The zinc finger domains of Ace 2 and Swi5 are highly conserved, with $83 \%$ identical residues and $95 \%$ similarity allowing conservative substitutions. Recently, Pavletich and Pabo (1991) solved the structure of a zinc finger-DNA cocrystal, and their data allow us to predict which amino acid residues of the Ace2 and Swi5 zinc fingers are likely to be involved in nucleotide sequence recognition. The amino acids predicted to contact DNA in Ace2 and Swi5 are identical, and we would therefore predict that Ace 2 and Swi5 would recognize the same DNA sequence. In support of this, we have obtained evidence that an Ace 2 zinc finger domain purified from $E$. coli binds in vitro to the Swi5-binding site at the HO promoter (R.M. Brazas and D.J. Stillman, unpubl.). The multicopy suppression experiments (Fig. 9) provide in vivo support for the idea that Ace 2 and Swi5 can bind to the same sequences. One experiment showed that $A C E 2$ overproduction can suppress the swi5 defect and allow $H O$ expression, and the reciprocal experiment showed that SWI5 overproduction overcomes the ace2 requirement for CTS1 expression. We have interpreted the results of these experiments as demonstrating that Ace 2 and Swi5 can bind in vivo to the HO and CTS1 promoters, respectively, although overproduction of a transcription factor could activate gene expression via an indirect mechanism.

If Ace2 and Swi5 do recognize the same DNA sequence with equal affinity, how are the ACE2/CTS1 pathway and the $S W I 5 / H O$ pathway kept separate? Under normal conditions in which the transcription factors are encoded by single-copy genes (either chromosomal or on CEN plasmids) there is no cross talk between the two pathways, under the conditions tested. We suggest that the zinc finger domains of Ace 2 and Swi5 are not sufficient to provide promoter specificity. The fact that the Ace2 : Swi5(Zn) chimera stimulates CTS1 expression (Fig. 10) suggests that the amino-terminal (non-zinc finger) domain of Ace 2 is needed for CTS1 activation. It is possible that additional proteins are needed to provide specificity in binding and that these proteins interact with the amino-terminal domains of Ace 2 and Swi5. Alternatively, the amino-terminal end of Ace2 may interact with a coactivator required for CTS1 expression, with which the Swi5 amino terminus fails to interact. The divergence in amino acid sequence between the aminoterminal domains of these two proteins is consistent with either of these ideas. We have preliminary evidence for such a factor, which we call Swi5 stimulatory factor (SSF). Swi5 binds with low affinity to the HO-binding site, and SSF increases the affinity of Swi5 for specific binding sites (R.M. Brazas and D.J. Stillman, in prep.). It remains to be seen whether SSF is responsible for the promoter specificity of Swi5 activating $\mathrm{HO}$ but not activating CTS1, and whether an analogous factor is needed for Ace2 binding to the CTS1 promoter.

\section{Materials and methods}

Strains and medium

Strains of $S$. cerevisiae used are listed in Table 2. A series of isogenic strains were derived from the $a / \alpha$ diploid DY866 (HO : lacZ ade2-1 ade6 can1-100 his3/ + his $4 /+$ leu2 trp1 ura3). The diploid strain was made heterozygous for ACE2 and 
Table 2. List of S. cerevisiae strains

\begin{tabular}{|c|c|}
\hline CG378 & $\begin{array}{l}\text { MATa ade5 can1 KIL-O leu2-3,112 trp1-289 } \\
\quad \text { ura3-52 }\end{array}$ \\
\hline DTY59 & 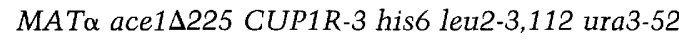 \\
\hline DY & $\begin{array}{l}\text { MATа } H O: \text { lacZ ade2-1 ade6 can1-100 his3-11,15 } \\
\quad \text { leu2-3,112 trp1-1 ura3 }\end{array}$ \\
\hline DY150 & $\begin{array}{l}\text { MATa ade2-1 can1-100 his3-11,15 leu2-3,112 } \\
\text { trp1-1 ura3-52 }\end{array}$ \\
\hline DY999 ${ }^{a}$ & $\begin{array}{l}\text { MATa } H O: \text { lacZ swi5 }: \text { TRP1 ade2-1 ade6 } \\
\text { can1-100 his3-11,15 leu2-3,112 trp1-1 ura3 }\end{array}$ \\
\hline DY1000 & $\begin{array}{l}\text { MAT } \alpha \text { HO : lacZ swi5 : TRP1 ade2-1 ade6 } \\
\quad \text { can1-100 his3-11,15 leu2-3,112 trp1-1 ura3 }\end{array}$ \\
\hline DY1114 ${ }^{\mathrm{a}}$ & $\begin{array}{l}\text { MATa } H O: \text { lacZ swi6D : TRP1 ade2-1 ade6 } \\
\text { can1-100 his3-11,15, leu2-3,112 trp1-1 ura3 }\end{array}$ \\
\hline DY $1115^{a}$ & $\begin{array}{l}\text { MATa } H O: \text { lacZ swi4D : LEU2 ade2-1 ade6 } \\
\quad \text { can1-100 his3-11,15 leu2-3,112 trp1-1 ura3 }\end{array}$ \\
\hline DY111 & $\begin{array}{l}\text { MAT } \alpha \text { HO : lacZ ade2-1 ade6 can1-100 his3-11,15 } \\
\text { leu2-3,112 trp1-1 ura3 }\end{array}$ \\
\hline DY1148 & $\begin{array}{l}\text { MATa } H O: \text { lacZ swi5D : TRP1 ace2A : HIS3 } \\
\text { ade2-1 ade6 can1-100 his3-11,15 leu2-3,112 } \\
\text { trp1-1 ura3 }\end{array}$ \\
\hline DY1 $149^{a}$ & $\begin{array}{l}\text { MAT } \alpha \text { HO : lacZ swi5D : TRP1 ace2D : HIS3 } \\
\text { ade2-1 ade6 can1-100 his3-11,15 leu2-3,112 } \\
\text { trp1-1 ura3 }\end{array}$ \\
\hline DY1150 & $\begin{array}{l}\text { MATa } H O: \text { lacZ ace2s : HIS3 ade2-1 ade6 } \\
\quad \text { can1-100 his3-11,15 leu2-3,112 trp1-1 ura3 }\end{array}$ \\
\hline DY $1151^{a}$ & $\begin{array}{l}\text { MAT } \alpha H O: \operatorname{lacZ} \text { ace } 2 \Delta: \text { HIS3 ade2-1 ade6 } \\
\text { can1-100 his3-11,15 leu2-3,112 trp1-1 ura3 }\end{array}$ \\
\hline
\end{tabular}

asogenic strains.

SWI5 by gene replacement (Rothstein 1991) with ace2A : HIS3 and swi5 : TRP1 null alleles. Haploid segregants differing only at the MAT, ACE2, and SWI5 loci were identified after tetrad dissection of the heterozygous diploid. The ace2s : HIS3 allele was created by the $\gamma$ gene disruption method of Sikorski and Heiter (1989). ACE2 sequences from the BglII site to the KpnI site (nucleotides +212 to +1764 , where the ATG is +1 ) have been deleted. The swi5 : TRP1 allele deletes DNA between the $B g I I I$ and NsiI sites, removing sequences extending from -875 to +1825 . Strains DY1114 (BY600) and DY1115 (BY606) were provided by Linda Breeden (Hutchison Cancer Research Center, Seattle, WA) and are isogenic to the strains derived from DY866. Strain DTY59 has been described previously (Butler and Thiele 1991). Strain CG378 was obtained from Dr. Craig Giroux (Wayne State University, Detroit, MI). Cells were grown either in rich YEPD medium or in synthetic complete media lacking either leucine (SC-Leu) or uracil (SC-Ura) for plasmid selection (Sherman 1991). Standard genetic methods were used for strain construction and tetrad analysis (Rothstein 1991; Sherman and Hicks 1991). Yeast cells were transformed by the method of Ito et al. (1983).

\section{Plasmid constructions}

A SWI5 fragment extending from -1209 to +2660 was cloned into pUC19 to create pUC19:SWI5. The KpnI site in pUC19 : SWI5 was destroyed by digestion with Asp 718 and filling in with Klenow, and the ClaI site of SWI5 was then converted to a $K p n I$ site using a $C l a \mathrm{I} / \mathrm{KpnI}$ adaptor (CGGTAC), thus creating pUC19:SWI5(ClaI-KpnI). This adds 2 amino acids to Swi5 but maintains the reading frame. SacI and SphI sites in the pUC19 polylinker were used to clone the SWI5 (ClaI-KpnI) fragment into YCplac33 (Gietz and Sugino 1988), thus creating
YCpSWI5(ClaI-KpnI). A 3.2-kb HpaI-HindIII fragment of ACE2 from pGB1-1 (Butler and Thiele 1991) was cloned into EcoRVHindIII-digested Bluescript KS + . This ACE2 fragment was then cloned as a SacI-HindIII fragment into YCplac33, thus creating YCpACE2. YCpSWI5:ACE2(Zn) and YCpACE2:SWI5(Zn) were created by exchanging the SacI-KpnI fragments, which contain the promoter and amino-terminal domain of each gene, between YCpSWI5(ClaI-KpnI) and YCpACE2. YEpSWI5 was constructed by replacing the SmaI-SphI fragment of YEp24 with the SWI5 fragment from pUC19: SWI5. YEpACE2 was constructed by replacing the SmaI-SalI fragment of YEp24 with a $3.65-\mathrm{kb}$ HpaI-SalI fragment from pGB1-1 (Butler and Thiele 1991). The entire promoter region of $S W I 5$ or ACE2 is present in constructs YCpSWI5(ClaI-KpnI), YCpACE2, YCpSWI5 : ACE2(Zn), YCpACE2 : $S W I 5(\mathrm{Zn}), \mathrm{YEp} S W I 5$, and YEpACE2.

YEp $A C E 2-$ lac $Z$, containing an in-frame $A C E 2-\beta$-galactosidase fusion, was constructed in several steps. First, a HindIII site was inserted between the last amino acid and the termination codon of the ACE2 ORF by site-directed mutagenesis ( $\mathrm{Su}$ and El-Gewely 1988). A 110-bp PvuII-HindIII fragment encompassing this region was then isolated and sequenced to ensure that no other fortuitous changes were introduced. This fragment was then used to reconstitute an $A C E 2$ gene fused in-frame to the $\beta$-galactosidase gene in the high-copy-number vector YEp367 (Myers et al. 1986), creating YEpACE2-lacZ. The fusion includes the entire ACE2 ORF and promoter region (to base -517 ; Butler and Thiele 1991).

\section{Indirect immunofluoresence}

Ten-milliliter cultures of cells were grown in synthetic complete media minus leucine ( $\mathrm{SC}-\mathrm{Leu}$ ) to an $\mathrm{OD}_{600}$ of $1-1.5$, fixed with formaldehyde, and stained with antibodies essentially as described in Pringle et al. (1991). The primary antibody (mouse monoclonal anti- $\beta$-galactosidase; Promega) was applied at 10 $20 \mu \mathrm{g} / \mathrm{ml}$. The secondary antibody, FITC (fluorescein 5-isothiocyanate)-conjugated sheep anti-mouse IgG (Boehringer Mannheiml, was used at a final concentration of $12-30 \mu \mathrm{g} / \mathrm{ml}$. To boost the signal, antibody staining was performed twice. Cells were treated first with the primary antibody for $1.5 \mathrm{hr}$, then with the secondary antibody for $1.5 \mathrm{hr}$, and the procedure was then repeated. DAPI (4', 6-diamidino-2-phenylindole dihydrochloride) was included in the mounting medium at a concentration of $45 \mathrm{ng} / \mathrm{ml}$ to stain nuclear DNA. Cells were visualized under $100 \times$ magnification using a Leitz Orthoplan microscope with an ultraviolet light source and were photographed with Kodak T-Max film at ASA 400. To arrest cells with nocodazole, $10 \mathrm{ml}$ of DTY 59 cells carrying YEpACE2-lacZ was grown to an $\mathrm{OD}_{600}$ of 1-1.5 in SC-Leu, and nocodazole (Sigma) was added to a final concentration of $15 \mu \mathrm{g} / \mathrm{ml}$ and $1 \%$ dimethylsulfoxide. Cells were incubated for an additional $2.5 \mathrm{hr}$, and at that time $>90 \%$ of the cells were arrested with large buds. To arrest with $\alpha$-factor, CG378 cells (MATa) transformed with YEpACE-lacZ were grown in $50 \mathrm{ml}$ of $\mathrm{SC}-\mathrm{Leu}$ to an $\mathrm{OD}_{600}$ of 0.3 and washed with sterile water to remove the Barl protease. Cells were incubated for an additional $1.5 \mathrm{hr}$ with $5 \mu \mathrm{g} / \mathrm{ml}$ of $\alpha$-factor (Sigma), until $\sim 70 \%$ arrested as small unbudded cells indicative of $G_{1}$ arrest. Cells arrested by either nocodazole or $\alpha$-factor were treated and stained as above for indirect immunofluorescence.

\section{RNA blot hybridization}

Total cellular RNA was prepared as described previously (Nasmyth 1983). Total RNA (1 $\mu \mathrm{g}$ ) was subjected to electrophoresis on a $1 \%$ agarose-formaldehyde gel, the gel was incubated in $10 \times$ SSC (twice, for $10 \mathrm{~min}$ each), and the RNA was trans- 
ferred to a nylon membrane (Gelman) by a capillary-transfer method (Maniatis et al. 1982). The RNA was then cross-linked to the nylon membranes using a Stratagene UV transilluminator. Hybridizations were carried out in $0.5 \mathrm{M} \mathrm{NaPO}_{4}(\mathrm{pH} 7.2), 1$ $\mathrm{mM}$ EDTA, $7 \%$ (wt $/ \mathrm{vol})$ SDS, and $1 \%$ (wt/vol) bovine serum albumin, at $65^{\circ} \mathrm{C}$ overnight. Following hybridization, filters were washed once at room temperature in $2 \times$ SSC $+0.1 \%$ SDS for $15 \mathrm{~min}$, once in $2 \times \mathrm{SSC}+0.1 \%$ SDS at $65^{\circ} \mathrm{C}$ for $15 \mathrm{~min}$, and once in $0.5 \times \mathrm{SSC}+0.1 \% \mathrm{SDS}$ at $65^{\circ} \mathrm{C}$ for $15 \mathrm{~min}$. Filters were blotted dry on $3 \mathrm{MM}$ (Whatman) filter paper, mounted in plastic bags, and exposed to Dupont Cronex film at $-70^{\circ} \mathrm{C}$ in the presence of an intensifying screen.

Hybridization probes were generated with a Random Primers DNA Labeling System (BRL) and $\left[\alpha^{-32} \mathrm{P}\right] \mathrm{dATP}(3000 \mathrm{Ci} / \mathrm{mmole}$, Amersham) from the following templates: for $A C E 2$, a 736-bp EcoRI-PvuII internal fragment of ACE2; for ACT1, BamHI-linearized pSP65ACT1 (kindly provided by Dave Eide, University of Minnesota, Duluth); for CTS1, a 950-bp fragment corresponding to nucleotides 544-1494 (where the ATG codon is +1 ); for $H 2 B$, an $\sim 950$-bp PvuII fragment from plasmid pCC68 (kindly provided by Fred Winston, Harvard Medical School, Cambridge, MA); for HO, a 875-bp HindIII-BamHI fragment containing the 5 ' end of the gene; and for SWI5, a 1591-bp NcoI-HindIII internal fragment.

For $\alpha$-factor synchrony experiments, yeast strain DY150 was grown in YEPD medium to an OD of $\leqslant 0.2$, and $\alpha$-factor (Sigma) was added to a concentration of $10 \mu \mathrm{g} / \mathrm{ml}$. Microscopic examination demonstrated that $>99 \%$ of the cells were unbudded after $195 \mathrm{~min}$, which is indicative of $\mathrm{G}_{1}$ phase arrest. The cells were filtered on a $0.22-\mu \mathrm{m}$ nitrocellulose filter and innoculated into fresh, prewarmed media. One $10-\mathrm{ml}$ aliquot was removed immediately prior to release from $\alpha$-factor arrest, and $10-\mathrm{ml}$ samples were removed at $10-\mathrm{min}$ intervals following release into fresh media. Part of each sample was sonicated and fixed in $3.7 \%$ formaldehyde for subsequent microscopic examination to evaluate cell cycle synchrony, and the remainder was used to prepare RNA.

\section{$\beta$-Galactosidase determinations}

Quantitative determinations of $\beta$-galactosidase activity were performed as described previously (Breeden and Nasmyth 1987). Each value reported is the average of determinations of at least three independent transformants.

\section{Acknowledgments}

We thank M. Kuranda and P. Robbins for communicating results in advance of publication, L. Breeden and T. Formosa for advice, R. Brazas, B. Graves, and G. Herrick for comments on the manuscript, and L. Breeden, D. Eide, R.D. Geitz, C. Giroux, A. Myers, R. Sikorski, and F. Winston for plasmids or strains. P.R.D. was a predoctoral trainee supported by National Cancer Institute National Research Service Award CA09602. This work was supported by National Institutes of Health grants RO1 GM41840 and RO1 GM39067 awarded to D.J.T. and D.J.S., respectively.

The publication costs of this article were defrayed in part by payment of page charges. This article must therefore be hereby marked "advertisement" in accordance with 18 USC section 1734 solely to indicate this fact.

\section{References}

Andrews, B. J. and I. Herskowitz. 1989. Identification of a DNA binding factor involved in cell-cycle control of the yeast $\mathrm{HO}$ gene. Cell 57: 21-29.
Breeden, L. and K. Nasmyth. 1987. Cell cycle control of the yeast $H O$ gene: cis- and trans-acting regulators. Cell 48: 389-397.

Breeden, L. and G.E. Mikesell. 1991. Cell cycle-specific expression of the SWI4 transcription factor is required for the cell cycle regulation of $\mathrm{HO}$ transcription. Genes \& Dev. 5: 11831190.

Butler, G. and D.J. Thiele. 1991. ACE2, an activator of yeast metallothionein expression which is homologous to SWI5. Mol. Cell. Biol. 11: 476-485.

Byers, B. 1981. Cytology of the yeast life cycle. The molecular biology of the yeast Saccharomyces cerevisiae. Cold Spring Harbor Laboratory, Cold Spring Harbor, New York.

Cabib, E. and R. Roberts. 1982. Synthesis of the yeast cell wall and its regulation. Annu. Rev. Biochem. 51: 763-793.

Ghiara, J.B., H.E. Richardson, K. Sugimoto, M. Henze, D.J. Lew, C. Wittenberg, and S.I. Reed. 1991. A cyclin B homolog in S. cerevisiae: Chronic activation of the $\mathrm{Cdc} 28$ protein kinase by cyclin prevents exit from mitosis. Cell 65: 163-174.

Gietz, R.D. and A. Sugino. 1988. New yeast-Escherichia coli shuttle vectors constructed with in vitro mutagenized yeast genes lacking six-base pair restriction sites. Gene 74: 527534.

Gutman, A. and B. Wasylyk. 1991. Nuclear targets for transcription regulation by oncogenes. Trends Genet. 7: 49-54.

Hayashi, S. and M.P. Scott. 1990. What determines the specificity of action of Drosophila homeodomain proteins? Cell 63: 883-894.

Hennessy, K.M., C.D. Clark, and D. Botstein. 1990. Subcellular localization of yeast CDC46 varies with the cell cycle. Genes \& Dev. 4: 2252-2263.

Hereford, L.M., M.A. Osley, J.R. Ludwig, and C.S. McLaughlin. 1981. Cell-cycle regulation of yeast histone mRNA. Cell 24: 367-375.

Herskowitz, I. 1988. Life cycle of the budding yeast Saccharomyces cerevisiae. Microbiol. Rev. 52: 536-553.

Ito, H., Y. Fukada, K. Murata, and A. Kimura. 1983. Transformation of intact yeast cells treated with alkali cations. $J$. Bacteriol. 153: 163-168.

Jacobs, C.W., A.E.M. Adams, P.J. Szaniszlo, and J.R. Pringle. 1988. Functions of microtubules in the Saccharomyces cerevisiae cell cycle. I. Cell Biol. 107: 1409-1426.

Jensen, R.E., G.F. Sprague Jr., and I. Herskowitz. 1983. Regulation of yeast mating-type interconversion: Feedback control of $H O$ gene by the mating-type locus. Proc. Natl. Acad. Sci. 80: 3035-3039.

Johnson, P.F. and S.L. McKnight. 1989. Eukaryotic transcriptional regulatory proteins. Annu. Rev. Biochem. 58: 799839.

Kuranda, M.J. and P.W. Robbins. 1991. Chitinase is required for cell separation during growth of Saccharomyces cerevisiae. J. Biol. Chem. 266: 19758-19767.

Lin, H. and M.F. Wolfner. 1991. The Drosophila maternal effect gene fs $(1)$ Ya encodes a cell-cycle dependent nuclear envelope component required for embryonic mitosis. Cell 64: 49-62.

Maniatis, T., E.F. Frisch, and J. Sambrook. 1982. Molecular cloning: A laboratory manual. Cold Spring Harbor Laboratory, Cold Spring Harbor, New York.

Moll, T., G. Tebb, U. Surana, H. Robitsch, and K. Nasmyth. 1991. The role of phosphorylation and the CDC28 protein kinase in cell cycle-regulated nuclear import of the S. cerevisiae transcription factor SWI5. Cell 66: 743-758.

Moreno, S. and P. Nurse. 1990. Substrates for p34cdc2: In vivo veritas? Cell 61: $549-551$.

Myers, A.M., A. Tzagoloff, D.M. Kinney, and C.J. Lusty. 1986. Yeast shuttle and integrative vectors with multiple cloning 
sites suitable for construction of lacZ fusions. Gene 45: 299 310.

Nasmyth, K. 1983. Molecular analysis of a cell lineage. Nature 302: $670-676$.

1987. The determination of mother cell-specific mating type switching in yeast by a specific regulator of $\mathrm{HO}$ transcription. EMBO I. 6: 243-248.

Nasmyth, K. and D. Shore. 1987. Transcriptional regulation in the yeast life cycle. Science 237: 1162-1170.

Nasmyth, K. and L. Dirick. 1991. The role of SWI4 and SWI6 in the activity of Gl cyclins in yeast. Cell 66: 996-1013.

Nasmyth, K., A. Seddon, and G. Ammerer. 1987. Cell cycle regulation of $S W I 5$ is required for mother-cell-specific $H O$ transcription in yeast. Cell 49: 549-558.

Nasmyth, K., G. Adolf, D. Lydall, and A. Seddon. 1990. The identification of a second cell cycle control on the HO promoter in yeast: Cell cycle regulation of SWI5 nuclear entry. Cell 62: 631-647.

Ogas, J., B.J. Andrews, and I. Herskowitz. 1991. Transcriptional activation of $C L N 1, C L N 2$, and a putative new G1 cyclin (HCS26) by SWI4, a positive regulator of Gl-specific transcription. Cell 66: 1015-1026.

Pavletich, N.P. and C.O. Pabo. 1991. Zinc finger-DNA recognition: Crystal structure of a Zif268-DNA complex at $2.1 \AA$ Science 252: 809-817.

Picard, D. and K.R. Yamamoto. 1987. Two signals mediate hormone-dependent nuclear localization of the glucocorticoid receptor. $E M B O$ f. 6: 3333-3340.

Pringle, J.R. and L.H. Hartwell. 1981. The Saccharomyces cerevisiae cell cycle. In The molecular biology of the yeast Saccharomyces cerevisiae. Cold Spring Harbor Laboratory, Cold Spring Harbor, New York.

Pringle, J.R., A.E.M. Adams, D.G. Drubin, and B.K. Harrer. 1991. Immunofluoresence methods for yeast. Methods Enzymol. 194: 565-602.

Rothstein, R. 1991. Targeting, disruption, replacement, and allele rescue: Integrative DNA transformation in yeast. Methods Enzymol. 194: 281-302.

Roux, P., J.-M. Blanchard, A. Fernandez, N. Lamb, P. Jeanteur, and M. Piechaczyk. 1990. Nuclear localization of c-fos, but not v-fos proteins, is controlled by extracellular signals. Cell 63: 341-351.

Sherman, F. 1991. Getting started with yeast. Methods Enzymol. 194: 1-21.

Sherman, F. and J. Hicks. 1991. Micromanipulation and dissection of asci. Methods Enzymol. 194: 21-38.

Sikorski, R.S. and P. Hieter. 1989. A system of shuttle vectors and yeast host strains designed for efficient manipulation of DNA in Saccharomyces cerevisiae. Genetics 122: 19-27.

Stern, M., R. Jensen, and I. Herskowitz. 1984. Five SWI genes are required for expression of the $\mathrm{HO}$ gene in yeast. J. Mol. Biol. 178: $853-868$.

Stillman, D.J., A.T. Bankier, A. Seddon, E.G. Groenhout, and K.A. Nasmyth. 1988. Characterization of a transcription factor involved in mother cell specific transcription of the yeast HO gene. EMBO I. 7: 485-494.

Strathern, J.N. and I. Herskowitz. 1979. Asymmetry and directionality in production of new cell types during clonal growth: The switching pattern of homothallic yeast. Cell 17: 371-381.

Su, T.Z. and M.R. El-Gewely. 1988. A multisite-directed mutagenesis using T7 DNA polymerase: Application for reconstructing a mammalian gene. Gene 69: 81-89.

Surana, U., H. Robitsch, C. Price, T. Schuster, I. Fitch, A.B. Futcher, and K. Nasmyth. 1991. The role of CDC28 and cyclins during mitosis in the budding yeast $S$. cerevisiae.
Cell 65: 145-161.

Thiele, D.J. 1988. ACE1 regulates expression of the Saccharomyces cerevisiae metallothionein gene. Mol. Cell. Biol. 8: $2745-2752$. 


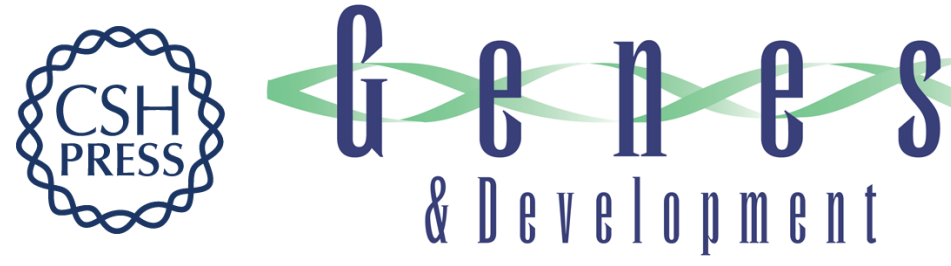

\section{Parallel pathways of gene regulation: homologous regulators SWI5 and ACE2 differentially control transcription of $\mathrm{HO}$ and chitinase.}

P R Dohrmann, G Butler, K Tamai, et al.

Genes Dev. 1992, 6:

Access the most recent version at doi:10.1101/gad.6.1.93

References This article cites 42 articles, 12 of which can be accessed free at:

http://genesdev.cshlp.org/content/6/1/93.full.html\#ref-list-1

License

Email Alerting

Service

Receive free email alerts when new articles cite this article - sign up in the box at the top right corner of the article or click here.

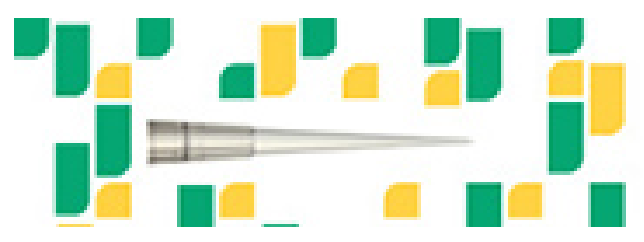

Focused on your science. 